\title{
Steuerermäßigung gemäß § 35 EStG für gewerbliche Einkünfte
}

$\S 35 \mathrm{EStG}$ ordnet für gewerbliche Personenunternehmen eine pauschalierte Anrechnung der Gewerbesteuer auf die Einkommensteuer an, mittels der eine weitgehende Gleichbehandlung gewerblicher und nicht gewerblicher Einkünfte erreicht bzw. die zusätzliche Belastung gewerblicher Gewinne durch die Gewerbesteuer kompensiert/abgemildert werden soll. Für Kapitalgesellschaften ist die Anwendung von § 35 EStG mit Blick auf den niedrigeren Tarif der Körperschaftsteuer ausgeschlossen. ${ }^{1}$

${ }^{1} \mathrm{Zu}$ Einzelheiten bzgl. § $35 \mathrm{EStG}$ siehe Teil I, Abschn. 12.7.1. 